\title{
Survey Study of Future Specialization Preference and the Factors Affecting the Choice of First, Second and Third Year Medical Students in College of Medicine, Baghdad University
}

\author{
Professor Dr. Numan Nafie Hameed ${ }^{1}$, Ayman Abdalridha Jaleal ${ }^{2}$, Ahmed \\ Yacob Yousef ${ }^{2}$, Ahmed Daib Ahmed ${ }^{2}$ \\ 1. Professor at Pediatrics Department, College of medicine, Baghdad University \\ 2. Third year student, College of medicine, Baghdad University
}

\begin{abstract}
Introduction: In recent years, there has been a growing appreciation of the issues of career preference in medicine as it may affect student learning and academic performance. However, few studies have been undertaken in medical schools in Iraq.

Objectives: we carried out this study to investigate the career preferences of medical students at college of medicine, university of Baghdad and determine factors that might influence their career decisions.

Methods: A cross-sectional questionnaire-based survey was carried out among first, second and third medical students at college of medicine, Baghdad university during the academic year 2015/2016. A total of 200 students answered the questionnaire which covered demographic characteristics, specialty preferences, and the factors that influenced these career preferences. Possible influences were selected on the basis of a literature review and discussions with groups of medical students and physicians. Students were asked to consider 14 specialty options and select the most preferred career preference.

Results: The most preferred specialty expressed by male students was internal medicine, followed by general surgery, while the specialty most preferred by female students was pediatrics followed by obstetrics and gynecology and general surgery. Students showed little interest in urology, ENT, and Psychiatry. Interesting subject of the specialty and the intellectual challenge were the most influential on their preference of specialty.

Conclusions: Surgery, internal medicine, pediatrics, and obstetrics and gynecology were the most preferred specialty preferences of medical students at college of medicine university of Baghdad.

Keywords: Medical students, Specialty preferences, Future carrier preferences

Correspondence: Professor Dr. Numan Nafie Hameed - College of Medicine, Baghdad University, and Consultant pediatrician in Children Welfare Teaching Hospital, Medical City Complex, Bab Al-Muadham, PO box 61023, Code, 12114 Baghdad (Iraq). Email:numanalhamdani@ Yahoo.com
\end{abstract}

\section{Introduction}

Medical education requires undergraduate students to study a wide range of medical specialties. It is often assumed that students do not make their career preferences until after they have graduated from medical school. However, not only medical school entrants [1], but even medical school applicants, often have strong preferences for or against some medical careers [2,3,4]. Much research has concentrated on the personal characteristics of individuals choosing particular careers [5,6], on background factors in childhood influencing career preference [7,8], and on associations with particular personality types [9]. Other research has concentrated on the careers of specific groups, such as women doctors [9], on attitudes towards specific specialties, such as psychiatry [10] and anesthesia [11,12], and on the basic statistics necessary for workforce planning [13].

With the continuing evolution of health care delivery and with advances in medical technology, the appropriate specialty mix within the medical workforce is still debated. Studying career preference can help provide important information to aid in planning educational programs, set priorities, and plan for the provision of adequate health care. The preference of medical specialties chosen by medical students plays an important part in the future work in health-care system. This study was conducted to record career preferences of first, second and third medical students at medical college, Baghdad university and investigate factors that might influence these career decisions.

\section{Subjects and Methods}

Setting and participants: A cross-sectional questionnaire-based survey was conducted among first, second and third year medical students via the internet at college of medicine, Baghdad university from 15 to 30 of April 2016. 
The questionnaire was administered to 65 first year students, 50 second year students, 150 third year students. The students were selected randomly. Of 265 questionnaires 65 were not answered. Response rates among first, second and third year medical students were $86.1 \%, 82 \%, 68.6 \%$ respectively.

Data Collection: The questionnaire covered demographic characteristics, specialty preferences, and factors that influenced career preferences. Possible influences were selected on the basis of literature reviews and discussions with medical students and physicians. Demographic characteristics included the student's age, gender, grade, and residency.

Students were asked to consider 13 specialty options In addition to the option (not decided yet) and select the most preferred career preference. Specialties listed were surgery, obstetrics and gynecology, pediatrics, internal medicine, psychiatry, orthopedics, ophthalmology, dermatology, radiology, neurosurgery, otolaryngology (ENT), urology, plastic surgery.

In the third part of the questionnaire influences on specialty preferences were indicated in order to assess the factors to which students attach importance when choosing their first specialty preferences. Responses to the influences were categorized to interesting subject, intellectual challenge, good income, prestige and good social life, advice from faculty or practicing physician or parents or friends. These influences were selected after reviewing related literature and conducting discussions with medical students and physicians.

Data Analysis: The Statistical Package for Social Sciences software (SPSS, version 20) was used to analyze the data. Differences in means were analyzed using independent sample t-test. Differences in proportions were analyzed using Chi-square test. A P-value of less than 0.05 was considered statistically significant.

\section{Results}

Basic demographics: Two hundred students participated in this survey. The percent of the third year students was $(51.5 \%)$ which is the most common percentage that contribute to this study then comes first year $(28.0 \%)$ and finally the second year $20.5 \%)$ from a sample of 125 female $(62.5 \%)$ and 75 male $(37.5 \%)$ medical students of Baghdad medical college. Sixty-two percent of the respondents were Females and Thirty-eight percent were males. Eighty-three percent were from Baghdad and Seventeen percent were from other governorates.

\section{Specialty preferences}

Nineteen percent (38/200) students not decided yet their future specialization. The most preferred specialty expressed by male students in spite of choice ( not decided yet) was internal medicine $(13.3 \%)$ followed by general surgery $(12 \%)$, while the specialty most preferred by female students in spite of choice ( not decided yet) was pediatrics $(16 \%)$ followed by obstetrics and gynecology $(10.4 \%)$ and general surgery $(10.4 \%)$. Students showed little interest in urology, ENT, and psychiatry. (Table 1),(figure 1)

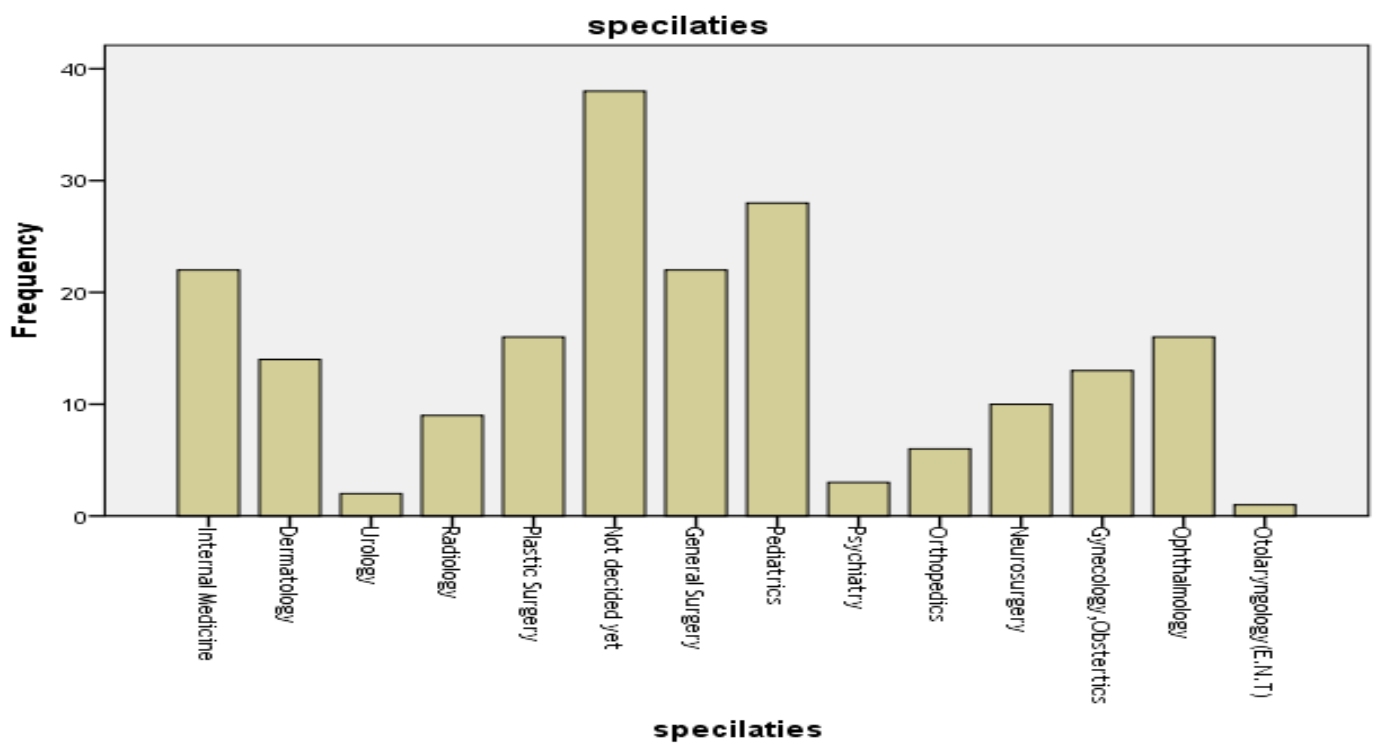

Figure 1: Specialization Preference of students 
Survey Study of Future Specialization Preference and the Factors Affecting the Choice of First, ..

Table 1: Frequency of Specialization Preference between male and female students

\begin{tabular}{|c|c|c|c|c|c|}
\hline \multicolumn{3}{|l|}{ Specialties } & \multicolumn{2}{|c|}{ male.female } & \multirow[t]{2}{*}{ Total } \\
\hline & male & female & \\
\hline & & $\%$ within male.female & $13.3 \%$ & $9.6 \%$ & $11.0 \%$ \\
\hline & \multirow[t]{2}{*}{ Dermatology } & Count & 4 & 10 & 14 \\
\hline & & $\%$ within male.female & $5.3 \%$ & $8.0 \%$ & $7.0 \%$ \\
\hline & \multirow[t]{2}{*}{ Urology } & Count & 0 & 2 & 2 \\
\hline & & $\%$ within male.female & $0.0 \%$ & $1.6 \%$ & $1.0 \%$ \\
\hline & \multirow[t]{2}{*}{ Radiology } & Count & 3 & 6 & 9 \\
\hline & & $\%$ within male.female & $4.0 \%$ & $4.8 \%$ & $4.5 \%$ \\
\hline & \multirow{2}{*}{ Plastic Surgery } & Count & 5 & 11 & 16 \\
\hline & & $\%$ within male.female & $6.7 \%$ & $8.8 \%$ & $8.0 \%$ \\
\hline & \multirow[t]{2}{*}{ Not decided yet } & Count & 14 & 24 & 38 \\
\hline & & $\%$ within male.female & $18.7 \%$ & $19.2 \%$ & $19.0 \%$ \\
\hline & \multirow[t]{2}{*}{ General Surgery } & Count & 9 & 13 & 22 \\
\hline & & $\%$ within male.female & $12.0 \%$ & $10.4 \%$ & $11.0 \%$ \\
\hline & \multirow[t]{2}{*}{ Pediatrics } & Count & 8 & 20 & 28 \\
\hline & & $\%$ within male.female & $10.7 \%$ & $16.0 \%$ & $14.0 \%$ \\
\hline & \multirow[t]{2}{*}{ Psychiatry } & Count & 1 & 2 & 3 \\
\hline & & $\%$ within male.female & $1.3 \%$ & $1.6 \%$ & $1.5 \%$ \\
\hline & \multirow[t]{2}{*}{ Orthopedics } & Count & 6 & 0 & 6 \\
\hline & & $\%$ within male.female & $8.0 \%$ & $0.0 \%$ & $3.0 \%$ \\
\hline & \multirow[t]{2}{*}{ Neurosurgery } & Count & 7 & 3 & 10 \\
\hline & & $\%$ within male.female & $9.3 \%$ & $2.4 \%$ & $5.0 \%$ \\
\hline & \multirow[t]{2}{*}{ Gynecology,Obstertics } & Count & 0 & 13 & 13 \\
\hline & & $\%$ within male.female & $0.0 \%$ & $10.4 \%$ & $6.5 \%$ \\
\hline & \multirow[t]{2}{*}{ Ophthalmology } & Count & 8 & 8 & 16 \\
\hline & & $\%$ within male.female & $10.7 \%$ & $6.4 \%$ & $8.0 \%$ \\
\hline & \multirow[t]{2}{*}{ Otolaryngology(E.N.T) } & Count & 0 & 1 & 1 \\
\hline & & $\%$ within male.female & $0.0 \%$ & $0.8 \%$ & $0.5 \%$ \\
\hline & \multirow[t]{2}{*}{ Total } & Count & 75 & 125 & 200 \\
\hline & & $\%$ within male.female & $100.0 \%$ & $100.0 \%$ & $100.0 \%$ \\
\hline
\end{tabular}

Table 2: Frequency of Specialization Preference among grade of students

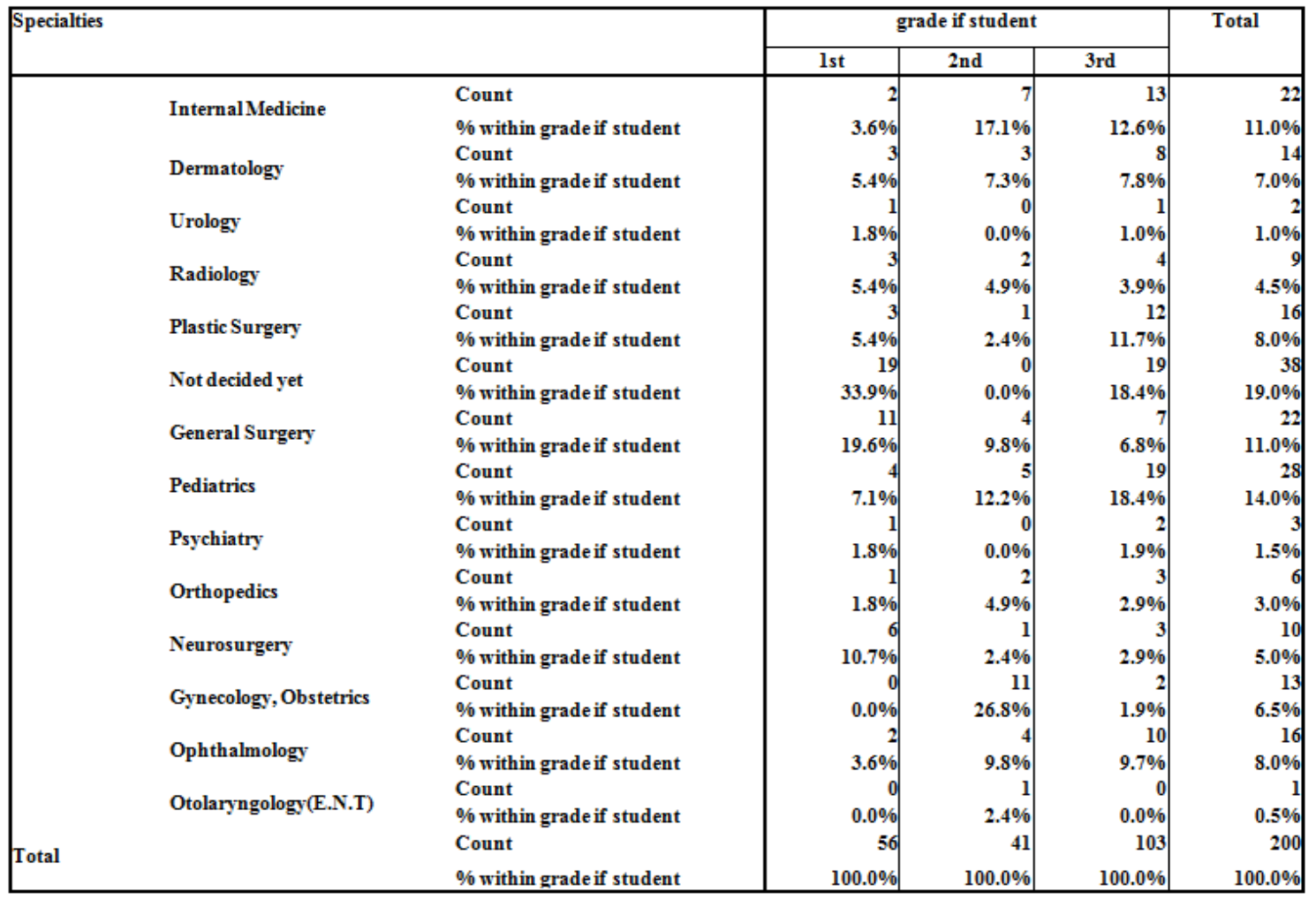


Survey Study of Future Specialization Preference and the Factors Affecting the Choice of First, ..

Factors that influence specialty preference

Interesting subject of the specialty $(59.5 \%)$ and the good income $(18.5 \%)$ were the most influential on their preference of specialty (table 3 ).

Table 3: Frequency of Factors Affecting the Choice of male and female students

\begin{tabular}{|c|c|c|c|c|c|}
\hline \multirow{2}{*}{\multicolumn{3}{|c|}{ Factors Affecting The Choice }} & \multicolumn{2}{|c|}{ male.female } & \multirow{3}{*}{$\begin{array}{r}\text { Total } \\
119 \\
\end{array}$} \\
\hline & & & \multirow{2}{*}{$\begin{array}{r}\text { male } \\
52\end{array}$} & \multirow{2}{*}{$\frac{\text { female }}{67}$} & \\
\hline & \multirow[b]{2}{*}{ interesting subject } & Count & & & \\
\hline & & $\%$ within male.female & $69.3 \%$ & $53.6 \%$ & $59.5 \%$ \\
\hline & \multirow[t]{2}{*}{ intellectual challenge } & Count & 6 & 31 & 37 \\
\hline & & $\%$ within male.female & $8.0 \%$ & $24.8 \%$ & $18.5 \%$ \\
\hline & \multirow[t]{2}{*}{ good income } & Count & 11 & 8 & 19 \\
\hline & & $\%$ within male.female & $14.7 \%$ & $6.4 \%$ & $9.5 \%$ \\
\hline & \multirow[t]{2}{*}{ prestige and good social life } & Count & 4 & 8 & 12 \\
\hline & & $\%$ within male.female & $5.3 \%$ & $6.4 \%$ & $6.0 \%$ \\
\hline & \multirow{2}{*}{$\begin{array}{l}\text { Advice from faculty, } \\
\text { practicing physicians, parents, } \\
\text { friends }\end{array}$} & Count & 2 & 11 & 13 \\
\hline & & \% within male.female & $2.7 \%$ & $8.8 \%$ & $6.5 \%$ \\
\hline \multirow{2}{*}{\multicolumn{2}{|c|}{ ( }} & Count & 75 & 125 & 200 \\
\hline & & $\%$ within male.female & $100.0 \%$ & $100.0 \%$ & $100.0 \%$ \\
\hline
\end{tabular}

\section{Discussion}

Career preferences made by medical students and factors influencing these preferences are of importance to medical workforce planners especially in times of oversupply or undersupply of doctors. Surgery, internal medicine, pediatrics, and obstetrics and gynecology were the most specialty preferred preferences among medical students at Baghdad medical college. The findings of this study were similar to these reported in other studies $[14,15]$.

Gender differences were noted in the preference of certain specialties. Female students preferred pediatrics and obstetrics and gynecology, but were less likely to choose orthopedics. This finding is in agreement with others $[9,16,17]$. it was reported that female students seemed to have a more idealistic approach than male students, and were less often influenced by the prospect of a good income or prestige.

Not surprisingly, it was noticed that no male students planed for a career of obstetrics and gynecology, likely caused by the look and character of the community that are often masculine. Otolaryngology (ENT) and urology and psychiatry were least popular specialty preferences. Although this survey did not follow up students, it was noticed that the distribution of students' first specialty preference often changed as they progressed through the course. First year medical students' preferences were inclined towards surgery with this specialty chosen as a first career preference by 11 of the students surveyed.

A wider distribution of first specialty preference was found among second year medical students but the widest was found among third year medical students. As first year medical students still did not have clinical experience, the majority of them tended to choose surgery, perhaps because of its perceived prestigious status among medical specialties. In contrast, third year medical students were more evenly spread in their preferences of specialty fields, which were less based on their social perceptions. Many researchers have tried to determine factors that Influence students' specialty preferences. Some have postulated that the primary influences were interesting subject whereas others have suggested other factors such as good income. Medical educators, however, have focused on educational influences such as curriculum, primary care experiences, and faculty role models. These influences are more readily modifiable than are such factors such as Institution's relative research intensity or students' long held values.

Surgery may lend itself more readily to the influence of role models. A surgeon who serves as a role model may be a parent or other relative, neighbor, personal physician, family friend, or medical school faculty members. Regardless of the source, role models were a powerful influence on the career preference of $22 \%$ of students in this study, with the majority being female students who preferred surgery. General surgery and its derivative specialties continue to appeal to graduating students in many countries $[18,19]$.

Several studies have cited clinical role models as being important influences on students' residency preferences [5,18,19]. This included negative role models, who drove students away from some specialties [19]. It is likely that a balance of factors operating before, during and after medical school is involved in any individual's career decision.

\section{Conclusions}

The most preferred specialty preferences of medical students at Baghdad medical college were Surgery, internal medicine, pediatrics, and obstetrics and gynecology. Future studies should consider the influences on the specialty preference of students from other institutions, across several clerkships, and over the early years of clinical practice. 
Abbreviations: ENT: ear, nose and throat.

\section{References}

[1]. Wright B, Scott I, Woloschuk W, Brenneis F, Bradley J: Career choice of new medical students at three Canadian universities: family medicine versus specialty medicine. CMAJ 2004; 170: 1920-24.

[2]. McManus IC, Lefford F, Furnham AF, Shahidi S, Pincus T: Career preference and personality differences in medical school applicants. Psychology, Health and Medicine 1996; 1: 235-48. 10.1080/13548509608402221.

[3]. Hutt R, Parsons D, Pearson R: The timing of and reasons for doctors' career decisions. Health Trends 1981; 13: 17-20.

[4]. Zeldow PB, Preston RC, Daugherty SR: The decision to enter a medical specialty: timing and stability. Medical Education 1992; 26: 327-32.

[5]. Saigal P, Takemura Y, Nishiue T, Fetters MD: Factors considered by medical students when formulating their specialty preferences in Japan: findings from a qualitative study. BMC Med Educ. 2007; 11: 7-31.

[6]. Pawełczyk A, Pawełczyk T, Bielecki J: The effect of some factors on medical student specialty choice of non-primary care-a synthesis of the literature. Pol Merkur Lekarski. 2007; 22: 575-9.

[7]. $\quad$ Paris J, Frank H: Psychological determinants of a medical career. Can J Psychiatry 1983; 28: 354-7.

[8]. Crimlisk H, McManus IC: The effect of personal illness experience on career preference in medical students. Medical Education 1987; 21: 464-7.

[9]. Dorsey ER, Jarjoura D, Rutecki GW: The influence of controllable lifestyle and sex on the specialty choices of graduating U.S. medical students, 1996-2003. Acad Med. 2005; 80: 791-6. 10.1097/00001888-200509000-00002.

[10]. Feifel D, Moutier C, Swerdlow N: Attitudes toward Psychiatry as a Prospective Career among Students Entering Medical School. Am J Psychiatry 1999; 156: 1397-402

[11]. Reeve PE: Personality characteristics of a sample of anaesthetists. Anaesthesia 1980; 35: 559-68. 10.1111/j.13652044.1980.tb03852.x.

[12]. Parkhouse J, Ellin DJ: Anaesthetics: career choices and experiences. Medical Education 1990; 24: 52-67.

[13]. Lambert T, Goldacre M, Parkhouse J: Doctors who qualified in the UK between 1974 and 1993: age, gender, nationality, marital status and family formation. Medical Education 1998; 32: 533-7. 10.1046/j.1365-2923.1998.00244.x.

[14]. Mariolis A, Mihas C, Alevizos A, Gizlis V, Mariolis T, Marayiannis K, Tountas Y, Stefanadis C, Philalithis A, Creatsas G: General Practice as a career choice among undergraduate medical students in Greece. BMC Medical Education. 2007, 7: 15-10.1186/14726920-7-15.

[15]. Avgerinos ED, Msaouel P, Koussidis GA, Keramaris NC, Bessas Z, Gourgoulianis K: Greek medical students' career choices indicate strong tendency towards specialization and training abroad. Health Policy. 2006, 79: 101-06. 10.1016/j.healthpol.2005.12.007.

[16]. Egerton EA: Career preferences enquiry among Queen's University Medical undergraduates and graduates: a follow-up. Medical Education 1983; 17: 105-11

[17]. McCord JH, McDonald R, Leverson G, Mahvi DM, Rikkers LF, Chen HC, Weber SM: Motivation to pursue surgical subspecialty training: is there a gender difference? J Am Coll Surg. 2007;205: 698-703. 10.1016/j.jamcollsurg.2007.06.014.

[18]. Buddeberg-Fischer B, Klaghofer R, Abel T, Buddeberg C: Swiss residents' speciality choices-impact of gender, personality traits, career motivation and life goals. BMC Health Serv Res. 2006, 23 (6): 137-10.1186/1472-6963-6-137.

[19]. Ambrozy DM, Irby DM, Bowen JL, Burack JH, Carline JD, Stritter FT: Role models' perceptions of themselves and their influences on students' specialty choices. Acad Med. 1997, 72: 1119-21. 10.1097/00001888-199712000-00028.

[20]. Khader Y, Al-Zoubi D, Amarin Z, Alkafagei A, Khasawneh M, et al: Factors affecting medical students in formulating their specialty preferences in Jordan. License BioMed Central Ltd. 2008, 10.1186/1472-6920-8-32. 